\title{
Predictive factors of failure to control bleeding and 6-week mortality after variceal hemorrhage in liver cirrhosis - a tertiary referral center experience
}

Daniela Matei ${ }^{1,2}$, Dana Crisan ${ }^{3}$, Bogdan Procopet ${ }^{1,2}$, Ioana Groza ${ }^{1,2}$, Bogdan Furnea ${ }^{1}$, Cristina Levi ${ }^{1}$, Marcel Tantau ${ }^{1,2}$

\author{
${ }^{1}$ Regional Institute of Gastroenterology and Hepatology "Prof. dr. Octavian Fodor", \\ Cluj-Napoca, Romania \\ ${ }^{2} 3^{\text {rd }}$ Medical Clinic, "Iuliu Hatieganu" University of Medicine and Pharmacy, \\ Cluj-Napoca, Romania \\ ${ }^{3} 5^{\text {th }}$ Medical Clinic, "Iuliu Hatieganu" University of Medicine and Pharmacy, \\ Cluj-Napoca, Clinical Municipal Hospital, Cluj-Napoca, Romania
}

Submitted: 2 June 2018; Accepted: 29 September 2018

Online publication: 11 January 2021

Arch Med Sci 2022; 18 (1): 52-61

DOI: https://doi.org/10.5114/aoms/97206

Copyright $\odot 2020$ Termedia \& Banach

\section{Abstract}

Introduction: Mortality from variceal bleeding remains high despite the therapeutic progress in severe cirrhosis. Understanding the predictive factors of failure to control bleeding (FTB) and mortality will lead to better future therapies. Comorbidities are thought to be important prognostic factors for variceal bleeding. The aim of the study was to assess the factors associated with FTB and with 42-day mortality and to evaluate the influence of comorbidities on these patients' prognosis.

Material and methods: We prospectively included in the study all consecutive patients with cirrhosis and variceal bleeding presenting to the emergency room and we followed them up over 6 weeks. CirCom score and Charlson index were used for the assessment of comorbidities.

Results: Of the 138 patients included in the study, 27 (19.5\%) were considered to have FTB. Child C class $(74.07 \%$ vs. $32.43 \%, p<0.001)$, Meld score (20.5 vs. $16.00, p=0.004)$ and creatinine level (1.04 vs. $0.81, p=0.01$ ) were associated with FTB, but only Child class was independently associated with FTB in multivariate analysis $(\mathrm{OR}=2.94, p=0.006)$. Mortality at 42 days $(21.7 \%)$ was influenced by the severity of the disease assessed through Child class $(76.66 \%$ vs. $30.55 \%$ - Child C, $p<0.001)$ and MELD score (21.00 vs. $16.00, p<0.001)$. Creatinine level (1.00 vs. $0.7, p=0.02)$ and acute kidney injury ( $26.66 \%$ vs. $7.40 \%, p=0.009)$ were also prognostic factors for the 6-week mortality. Comorbidities did not influence the mortality (CirCom $>1(16.7 \%$ vs. $21.3 \%, p=0.76)$ or Charlson index $>4(36 \%$ vs. $47.2 \%, p=0.41)$.

Conclusions: The severity of cirrhosis is an important prognostic factor for FTB and 42-day mortality. Identifying the factors associated with early mortality may help selecting patients needing more than conventional therapy.

Key words: variceal bleeding, cirrhosis, failure to control bleeding, mortality, predictive factors.

\author{
Corresponding author: \\ Dana Crisan \\ ${ }^{2} 3^{\text {rd }}$ Medical Clinic \\ "Iuliu Hatieganu" University \\ of Medicine and Pharmacy \\ 8 Babes Street \\ Cluj-Napoca, Romania \\ Phone +40 374834114 \\ E-mail: crisan.dc@gmail.com
}




\section{Introduction}

Acute variceal hemorrhage is a major complication of liver cirrhosis and is responsible for one third of cirrhosis deaths [1, 2]. The Child-TurcottePugh score and the Model for End Stage Liver Disease (MELD), proven to have a prognostic value in liver cirrhosis [3, 4], have also been validated for the clinical course of variceal hemorrhage [5-7].

Although insufficiently validated, the presence of comorbidities cannot be ignored when discussing short-term mortality. Some research groups have already included in mixed scores the different variables that seem to influence the prognosis of liver cirrhosis patients (CirCom) [8].

On the other hand, the recent progress in the therapeutic means for variceal hemorrhage (band ligation, vasoactive medication, antibiotic treatment) [9-14] has led to better control of bleeding; as a result, the natural history and prognosis of these patients can be different from the data published previously. The studies report values of mortality between $16 \%$ and $24 \% 6$ weeks after the bleeding episode; these values have improved in the past few years but are still high enough to be disturbing and to motivate the continuing research on the risk factors and treatment. The key moment to calculate the prognosis is 6 weeks after the variceal hemorrhage, since the risk of death of patients after this threshold becomes similar to that of patients who have never bled $[2,15,16]$.

The aim of this prospective, observational study was:

- to assess the factors that are associated with failure to control bleeding and with 42-day mortality,

- to evaluate the influence of comorbidities on failure to control bleeding and 42-day mortality.

\section{Material and methods}

\section{Patient selection criteria}

We included in the study all consecutive patients presenting to the Emergency Department of our tertiary medical centre (the Regional Institute of Gastroenterology and Hepatology "Prof. Dr. Octavian Fodor", Cluj-Napoca, Romania) with upper gastrointestinal bleeding (UGIB) of variceal origin between November 2012 and July 2013. It is worth noting that our hospital is the reference centre for the endoscopic treatment of upper digestive bleeding in the entire region (including almost 7 million inhabitants). All patients were prospectively followed over a period of 6 weeks. The inclusion criteria were the following: liver cirrhosis diagnosis, hematemesis and/or melena, bleeding of variceal origin, age above 18 years and informed consent signed. Patients having different complications of cirrhosis, including hepatocarcinoma, were not excluded from the study.

Cirrhosis was diagnosed using unequivocal clinical (palmar erythema, spider nevi, gynecomasty, hepatomegaly with sharp anterior margin, splenomegaly, ascites, edema, encephalopathy), laboratory and imaging criteria (irregular liver contour, splenomegaly, ascites, perigastric and pericholecystic collateral circulation and in the spleen hilum, recanalization of the round ligament). Acute kidney injury (AKI) was defined as serum creatinine $\geq 1.5 \mathrm{mg} / \mathrm{dl}$ according to the existing guidelines at the moment of inclusion [17].

The study was performed in accordance with the Helsinki declaration and was approved by the Ethics Committee of the Hospital. All patients signed an informed consent form.

\section{Patient management}

Demographic and clinical data considered relevant for liver cirrhosis were recorded for each patient upon admission, as well as their comorbidities. Hemodynamic instability was defined as either arterial hypotension (blood pressure below $90 \mathrm{~mm} \mathrm{Hg}$ ) or tachycardia (heart rate above 100 beats/min).

Esophagogastroduodenoscopy was performed in each patient in the first $12 \mathrm{~h}$ with an Olympus Exera II CLE165 device. Because of the hemodynamic instability in 4 cases endoscopy was performed within $24 \mathrm{~h}$ (between 11 and $19 \mathrm{~h}$ ). After confirming the variceal site of the bleeding, band ligation and/or sclerotherapy (for gastric varices) were performed. In case of failure to control bleeding (FTB) or rebleeding, the endoscopy was repeated, as well as the band ligation. The balloon tamponade $(n=13)$ was used in the case of massive bleeding where an effective endoscopic treatment could not be performed. Beside the endoscopic treatment, all patients received vasoactive medication (Sandostatin $50 \mu \mathrm{g}$ bolus followed by continuous infusion of $50 \mu \mathrm{g} / \mathrm{h}$ or terlipressin $2 \mathrm{mg}$ i.v. bolus followed $1 \mathrm{mg}$ every $6 \mathrm{~h}$, for up to 5 days) and all patients received antibiotic treatment (IV $3^{\text {rd }}$ generation cephalosporins for at least 5 days). Secondary prophylaxis was started on the $6^{\text {th }}$ day after controlling the bleeding episode and was performed using a non-selective $\beta$-blocker (propranolol with a starting dose of $40 \mathrm{mg} /$ day and titrated up to $120 \mathrm{mg} /$ day) treatment and endoscopic band ligation.

When assessing comorbidities, we used both the CirCom [8] score, which quantifies conditions with an impact on cirrhosis progression, and the Charlson comorbidity index [18], which quantifies conditions with an impact on any other disease. Considering that all patients had liver cirrhosis, in calculating the Charlson index all patients 
were attributed at least 3 points. For each of the 2 scores used, the patients were divided into 2 groups: without comorbidities and with at least one comorbidity.

\section{Patient follow-up}

All patients were followed for 6 weeks. According to the Baveno $\mathrm{V}$ recommendation, the time interval used to define the acute bleeding episode was 5 days and failure to control bleeding was defined as follows: death or need to change therapy defined by one of the following criteria:

- fresh hematemesis or NG aspiration of $\geq 100 \mathrm{ml}$ of fresh blood $\geq 2 \mathrm{~h}$ after the start of a specific drug treatment or therapeutic endoscopy,

- development of hypovolaemic shock,

- $3 \mathrm{~g}$ drop in $\mathrm{Hb}$ within any $24 \mathrm{~h}$ period if no transfusion was administered [19].

\section{Statistical analysis}

The statistical analysis was performed using the SPSS software, version 20, Chicago, IL, USA. Nominal variables were characterized using frequencies. Quantitative variables were described by mean and standard deviation or by median and

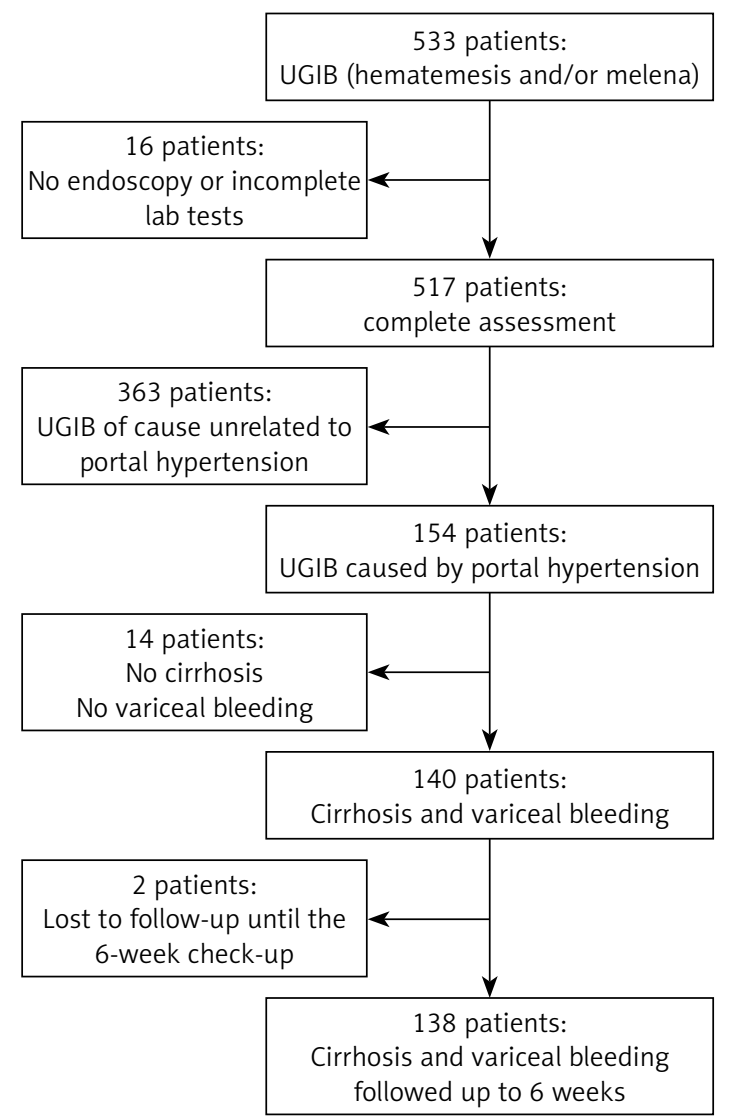

Figure 1. Flow chart of the patients included in the study

UGIB - upper gastrointestinal bleeding.
IQR, as appropriate. The level of statistical significance was set at $p<0.05$. Differences of frequencies between nominal variables were assessed with the $\chi^{2}$ test or Fisher exact test. Continuous variables were compared using the Student $t$ or Mann-Whitney test, as appropriate. Multivariate analysis was performed using logistic regression. We included in the univariate analysis the parameters reaching a significance level $p<0.05$. The cutoff value was chosen for maximal sensitivity and specificity. We calculated the sensibility, specificity, positive predictive value and negative predictive values for the cutoff value of the score.

\section{Results}

Between November 2012 and July 2013, 533 patients with upper gastrointestinal bleeding (hematemesis and/or melena) presented to the Emergency Department of the Regional Institute of Gastroenterology and Hepatology "Prof. Dr. Octavian Fodor". Of these, 16 did not undergo upper digestive endoscopy and were excluded from the study. In 154 patients, the cause of the UGIB was related to the portal hypertension, but 14 did not have cirrhosis or the origin of the bleeding was other than esophageal varices. The remaining 140 patients had both liver cirrhosis and variceal bleeding. Two patients were lost from the study until the 6-week check-up. It follows that $138 \mathrm{pa}$ tients were included in the final analysis (Figure 1). Among them, 49 (35.5\%) had previous variceal bleeding and were under secondary prophylaxis with nonselective $\beta$-blocker (NSBB) and endoscopic band ligation.

Baseline characteristics of the patients included in the study are presented in Table I. The male gender was dominant, with a median age of 58 years; the ethanolic etiology was highly prevalent, 74 (53.6\%) were at the first episode of variceal hemorrhage, 51 (37\%) patients had hepatic encephalopathy, 74 (53.6\%) had ascites, $13(9.42 \%)$ had hepatocarcinoma. The anemia found in patients was on average of moderate severity; patients needed a total quantity of 34 units of blood, with a mean of $2.71 \pm 2.6$. At the inclusion in the study, 16 (11.59\%) patients had AKI (creatinine $>1.5 \mathrm{mg} / \mathrm{dl}$ ). We found an equal distribution between Child $B$ and $C$ patients.

\section{Failure to control bleeding}

In our study group, 27 patients (19.5\%) were considered to have failure of bleeding control. Sixteen $(59.27 \%)$ patients of those with uncontrolled hemorrhage died, but all had been hemodynamically unstable at presentation. Eight of them had fresh hematemesis. A decrease of $>3 \mathrm{~g}$ in hemoglobin $48 \mathrm{~h}$ from admission was found in 
$3(11.11 \%)$ patients. Blood transfusion had a significant association with the control of bleeding (2.40 \pm 2.1 vs. $4.21 \pm 2.85$ in FTB group; $p=0.02$ ). Of the comorbidities, diabetes mellitus was present in 28 patients in the whole study group, only 3 patients from FTB group having diabetes. The etiology of cirrhosis had no influence on variceal bleeding control $(p=0.11)$. The factors associated with failure to control bleeding are presented in Table II.

According to the clinical criteria of patients defined as high risk for failure to control bleeding (Child C or Child B plus active bleeding) [19], in our population, only Child $C$ class of severity significantly predicted the FTB $(20(74.07 \%)$ vs. 36 (32.43\%), $p=0.002$ ). Child B patients bleeding actively during endoscopy did not have a higher rate of FTB $(p=0.15)$; nor did Child B plus C patients who presented active bleeding (16 (59.25\%) vs. 44 (39.63\%), $p=0.10)$.

Time from symptoms onset to endoscopy was significantly shorter in patients with FTB (9.24 (6.60-17.16)) vs. patients without FTB (14.70 (7.36-28.25)), $p=0.04$, due to the more rapid transfer of severe patients to the endoscopy department. In multivariate analysis, only the Child class was significantly associated with failure to control bleeding, which is a marker of the real influence of the severity of the main disease. When the time from admission in the hospital to endoscopy was analyzed, we found no difference between patients with and without FTB (2.48 (1.30-4.62) vs. 1.72 (1.23-3.38)), $p=0.17$. The difference is created by the interval between symptoms onset and admission in the hospital, which is significantly shorter in severe patients: 8.77 (4.63-24.00) vs. 13.22 (4.90-25.00), $p=0.09$. Patients with a lower Charlson score had a higher rate of FTB without reaching statistical significance (1 patient from the group with failure vs. 9 patients from the group without failure, $p=0.47$ ), suggesting that comorbidities are less important for bleeding control than the severity of the disease.

As mentioned before, in multivariate analysis, only the severity of the disease expressed through Child class was independently associated with failure to control bleeding (Table III). In order to avoid collinearity, we did not include encephalopathy, ascites or INR in multivariate analyses, since they are variables of the Child-Pugh score.

\section{Forty-two day mortality}

The next objective was to analyze the factors associated with 42-day mortality. Thirty (21.7\%) patients died during the first 6 weeks: 19 (63.3\%) from uncontrolled bleeding, 9 (30\%) due to hepatic failure and $2(6.6 \%)$ due to ventricular fibrilla-
Table I. Baseline characteristics of study group

\begin{tabular}{|c|c|}
\hline Variable & Mean \pm SD/Median (IQR) \\
\hline Age [years] & $58.00(52.00 ; 65.00)$ \\
\hline Gender (M) (\%) & $95(68.8)$ \\
\hline \multicolumn{2}{|l|}{ Etiology, $n(\%)$ : } \\
\hline Viral & $34(24.6)$ \\
\hline Ethanolic & $81(58.7)$ \\
\hline Mixed & $15(10.9)$ \\
\hline Other & $8(5.8)$ \\
\hline Hemoglobin [g/dl] & $9.30(7.63 ; 11.50)$ \\
\hline Platelets $\left[\times 10^{9}\right]$ & $101.00(69.25 ; 130.00)$ \\
\hline $\mathrm{ALT}[\mathrm{U} / \mathrm{I}]$ & $28.00(18.00 ; 43.50)$ \\
\hline AST [U/I] & $60.50(40.00 ; 104.50)$ \\
\hline Creatinine $[\mathrm{mg} / \mathrm{dl}]$ & $0.85(0.61 ; 1.42)$ \\
\hline Total bilirubin & $2.70(1.50 ; 6.55)$ \\
\hline Albumin $[\mathrm{g} / \mathrm{dl}]$ & $2.92 \pm 0.66$ \\
\hline INR & $1.88(1.51 ; 2.60)$ \\
\hline Ascites, $n(\%)$ & $74(53.6)$ \\
\hline Encephalopathy, $n$ (\%) & $51(37)$ \\
\hline \multicolumn{2}{|l|}{ Child, $n(\%)$ : } \\
\hline$A$ & $27(19.6)$ \\
\hline B & $55(39.9)$ \\
\hline C & $66(40.6)$ \\
\hline MELD & $16.00(13.00 ; 20.00)$ \\
\hline
\end{tabular}

tion. As mentioned, 16 (53.33\%) patients died in the first 5 days.

The factors associated with 42-day mortality are presented in Table IV.

Again, the most important factors associated with 42-day mortality are those related to the severity of the disease. The MELD score and the Child class were significantly associated in univariate analysis with death at 6 weeks after UGIB ( $p<0.001$ in both cases). We found the MELD $>18$ cutoff to be predictive of death (sensitivity $69 \%$, specificity $72.6 \%$ ).

It is worth noting that AKI had a significant influence on 6-week survival $(p=0.009)$. In addition, AKI was significantly correlated with the presence of ascites $(p=0.01)$. Failure to control bleeding at 5 days was also significantly associated with 42day mortality $(p<0.001)$. Of the patients defined as high risk for failure to control bleeding, only the Child $C$ severity class had a significant influence on mortality prediction $(p=0.001)$. Patients from Child B class with active bleeding at endoscopy 
Table II. Univariate analysis associated with failure to control bleeding

\begin{tabular}{|c|c|c|c|}
\hline \multirow[t]{2}{*}{ Variable } & \multicolumn{2}{|c|}{ Failure to control bleeding } & \multirow[t]{2}{*}{$P$-value } \\
\hline & Yes $(n=27)$ & No $(n=111)$ & \\
\hline First episode of bleeding, $n(\%)$ & $21(77.77)$ & $68(61.26)$ & $0.16^{*}$ \\
\hline Arterial hypotension, $n(\%)$ & $3(11.11)$ & $5(4.50)$ & $0.39^{\star}$ \\
\hline Tachycardia, $n(\%)$ & $16(59.25)$ & $42(37.83)$ & $0.07^{\star}$ \\
\hline Hemodynamic instability, $n(\%)$ & $17(62.96)$ & $45(40.54)$ & $0.05^{*}$ \\
\hline $\begin{array}{l}\text { Active bleeding at endoscopy, } \\
n(\%)\end{array}$ & $4(14.81)$ & $30(27.02)$ & $0.18^{*}$ \\
\hline High risk of $\mathrm{FTB}^{\S}$ & $0(0)$ & $12(10.81)$ & $0.15^{*}$ \\
\hline Creatinine $[\mathrm{mg} / \mathrm{dl}]$ & $1.04(0.73 ; 1.95)$ & $0.81(0.60 ; 1.32)$ & $0.01^{* *}$ \\
\hline Creatinine $>1.5, n(\%)$ & $7(25.92)$ & $9(8.10)$ & $0.02^{*}$ \\
\hline Total bilirubin [mg/dl] & $4.10(1.60 ; 10.00)$ & $2.70(1.47 ; 6.10)$ & $0.15^{\star *}$ \\
\hline Albumin [g/dl] & $2.60(2.32 ; 2.95)$ & $3.10(2.60 ; 3.40)$ & $0.03^{* *}$ \\
\hline INR & $2.13(1.59 ; 3.04)$ & $1.83(1.51 ; 2.22)$ & $0.10^{* *}$ \\
\hline Prothrombin time (s) & $30.70(22.15 ; 41.25)$ & $25.00(22.00 ; 31.00)$ & $0.14^{\star \star}$ \\
\hline Ascites, $n(\%)$ & $17(62.96)$ & $54(48.64)$ & $0.38^{*}$ \\
\hline Hepatic encephalopathy, $n(\%)$ & $18(66.66)$ & $33(29.72)$ & $<0.001^{*}$ \\
\hline \multicolumn{4}{|l|}{ Child class, $n(\%):$} \\
\hline$A$ & $2(7.40)$ & $25(22.52)$ & \\
\hline $\mathrm{B}$ & $5(18.51)$ & $50(45.04)$ & $<0.001^{*}$ \\
\hline C & $20(74.07)$ & $36(32.43)$ & \\
\hline MELD & $20.5(16.00 ; 26.00)$ & $16(13.00 ; 19.00)$ & $0.004^{\star *}$ \\
\hline Charlson & $3(3 ; 7)$ & $3(3 ; 6)$ & $0.10^{4}$ \\
\hline Charlson $\geq 4, n(\%)$ & $1(3.70)$ & $9(8.10)$ & $0.70^{*}$ \\
\hline CirCom & $0(0 ; 2)$ & $0(0 ; 1)$ & $0.41^{\prime}$ \\
\hline CirCom $\geq 1, n(\%)$ & $4(14.81)$ & $24(21.62)$ & $0.60^{*}$ \\
\hline
\end{tabular}

${ }^{\$}$ High risk of failure to control bleeding = Child $B+$ active bleeding. "Values expressed as median (min; max), *values expressed as $n$ (\%), ${ }^{* *}$ values expressed as median $\left(25^{\text {th }} ; 75^{\text {th }}\right.$ percentiles), ${ }^{* * *}$ values expressed as mean \pm SD. FTB - failure to control bleeding.

did not have a higher mortality risk in our study $(p=0.41)$, only when considering Child B plus C with active bleeding together (20 (66.66\%) vs. 40 (37.08\%), $p=0.007)$.

In order to avoid data collinearity, for multivariate analysis, we created two different models, one of them including the Child class while the other included the MELD score. In both models, we did not include the variables used for calculating Child and MELD scores, but only the score values, so as not to insert the variables twice in the analysis. In the first model, including the Child class, only the severity of the disease expressed by the Child score was independently associated with mortality at 6 weeks $(p=0.0005, \mathrm{OR}=4.28,95 \% \mathrm{Cl}$ : 1.87-9.77), while in the second model, the MELD score $(\mathrm{OR}=1.10,95 \% \mathrm{Cl}: 1.01-1.21, p=0.02)$ and encephalopathy $(\mathrm{OR}=4.23,95 \% \mathrm{Cl}: 1.50-11.94$,

Table III. Multivariate analysis of factors associated with failure to control bleeding

\begin{tabular}{|lccc|}
\hline Variable & Odds ratio & $95 \% \mathrm{Cl}$ & $P$-value \\
\hline Child class & 2.94 & $1.34-6.43$ & 0.006 \\
\hline Creatinine $[\mathrm{mg} / \mathrm{dl}]$ & 2.15 & $0.81-5.68$ & 0.12 \\
\hline Hemodynamic instability & 1.75 & $0.69-4.45$ & 0.23 \\
\hline
\end{tabular}


Table IV. Univariate analysis of factors associated with 42-day mortality

\begin{tabular}{|c|c|c|c|}
\hline \multirow[t]{2}{*}{ Variable } & \multicolumn{2}{|c|}{ 42-day check-up } & \multirow[t]{2}{*}{$P$-value } \\
\hline & Dead $(n=30)$ & Survived $(n=108)$ & \\
\hline First episode of bleeding, $n(\%)$ & $23(76.66)$ & $66(61.11)$ & $0.17^{\star}$ \\
\hline Arterial hypotension, $n(\%)$ & $3(10)$ & $5(4.6)$ & $0.50^{*}$ \\
\hline Tachycardia, $n(\%)$ & $19(63.3)$ & $39(36.1)$ & $0.01^{*}$ \\
\hline $\begin{array}{l}\text { Active bleeding during } \\
\text { endoscopy, } n(\%)\end{array}$ & $10(33.3)$ & $27(25)$ & $0.49^{\star}$ \\
\hline High risk of $\mathrm{FTB}^{\S}, n(\%)$ & $1(3.33)$ & $11(10.18)$ & $0.41^{*}$ \\
\hline Creatinine $[\mathrm{mg} / \mathrm{dl}]$ & $1(0.7 ; 1.6)$ & $0.7(0.6 ; 1)$ & $0.02^{* *}$ \\
\hline Creatinine $>1.5, n(\%)$ & $8(26.66)$ & $8(7.40)$ & $<0.001^{*}$ \\
\hline Total bilirubin [mg/dl] & $3.9(2.2 ; 6.2)$ & $2.0(1.3 ; 4.0)$ & $<0.001^{* *}$ \\
\hline Albumin $[\mathrm{g} / \mathrm{dl}]$ & $2.5 \pm 0.5$ & $3.00 \pm 0.7$ & $0.001^{* * *}$ \\
\hline INR & $2.14(1.66 ; 2.66)$ & $1.60(1.49 ; 1.89)$ & $0.001^{* *}$ \\
\hline Prothrombin time [s] & $32.45(26.9 ; 42.8)$ & $24.50(21.8 ; 29.3)$ & $0.002^{\star *}$ \\
\hline Ascites, $n(\%)$ & $20(66.7)$ & $79(73.2)$ & $0.64^{*}$ \\
\hline Hepatic encephalopathy, $n$ (\%) & $21(70)$ & $30(27.8)$ & $<0.001^{*}$ \\
\hline \multicolumn{4}{|l|}{ Child class, $n(\%)$ : } \\
\hline$A$ & $1(3.33)$ & $26(24.07)$ & \\
\hline $\mathrm{B}$ & $6(20.00)$ & $49(45.37)$ & $<0.001^{\star}$ \\
\hline $\mathrm{C}$ & $23(76.66)$ & $33(30.55)$ & \\
\hline MELD score & $21(17.5 ; 27.5)$ & $16(13 ; 19)$ & $<0.001^{\star *}$ \\
\hline Charlson index & $3(3 ; 7)$ & $3(3 ; 6)$ & $0.30^{4}$ \\
\hline Charlson > 4, n (\%) & $11(36.7)$ & $51(47.2)$ & $0.41^{*}$ \\
\hline CirCom & $0(0 ; 2)$ & $0(0 ; 1)$ & $0.54^{\prime \prime}$ \\
\hline CirCom > $1, n(\%)$ & $5(16.7)$ & $23(21.3)$ & $0.76^{\star}$ \\
\hline Failure to control bleeding, $n(\%)$ & $20(66.66)$ & $5(4.62)$ & $<0.001^{\star}$ \\
\hline
\end{tabular}

${ }^{\S}$ High risk of failure to control bleeding $=$ Child $B+$ active bleeding. "Values expressed as median (min; max), *values expressed as $n$ (\%), ${ }^{* *}$ values expressed as median $\left(25^{\text {th }} ; 75^{\text {th }}\right.$ percentiles), ${ }^{* * *} v$ values expressed as mean \pm SD. FTB - failure to control bleeding.

$p=0.006)$ were independently associated with mortality $(p=0.02$ and $p=0.006$ respectively; Table $\vee \mathrm{A}, \mathrm{B})$.

\section{Discussion}

The present study proves that comorbidities (quantified using the Charlson and CirCom scores) do not influence the short-term prognosis of patients with variceal bleeding. The highest prognostic value is held by the liver function (Child and MELD scores) but the occurrence of AKI should definitely not be neglected. We find the validation of the prognostic factors for patients with variceal bleeding on an Eastern European population to be essential, when we consider the geographical, genetic and lifestyle differences, which greatly in-
Table V A, B. Multivariate analysis of factors associated with 42-day mortality (V A including Child class; $V$ B including MELD score)

A

\begin{tabular}{|lccc|}
\hline Variable & Odds ratio & $95 \% \mathrm{Cl}$ & $P$-value \\
\hline Child class & 4.28 & $1.87-9.77$ & $<0.001$ \\
\hline Creatinine $[\mathrm{mg} / \mathrm{dl}]$ & 2.64 & $1.00-6.91$ & 0.04 \\
\hline
\end{tabular}

\begin{tabular}{|lccc|}
\hline Variable & Odds ratio & $95 \% \mathrm{Cl}$ & $\boldsymbol{P}$-value \\
\hline MELD & 1.10 & $1.01-1.21$ & 0.02 \\
\hline Encephalopathy & 4.23 & $1.50-11.94$ & 0.006 \\
\hline Albumin [g/dl] & 0.89 & $0.34-2.37$ & 0.82 \\
\hline
\end{tabular}


fluence the etiology of liver cirrhosis and the pathology of variceal bleeding [20, 21].

When assessing the 6-week mortality, the impossibility to control bleeding in the first days after the bleeding episode is of the utmost importance. Several studies have analyzed the factors associated with 5-day rebleeding or continued bleeding; some of these include active bleeding at endoscopy [14, 22, 23], variceal size [24], ChildPugh class [12, 14, 22, 24, 25], hematocrit level $[14,26]$, bacterial infections $[22,26]$, hepatic encephalopathy [27], portal vein thrombosis [14], the presence of hepatocellular carcinoma [26], and hypoalbuminemia [22]. Our study confirms these data (Table II). Lately, there is a debate regarding the most important prognostic factors that would indicate the need for further interventions, such as transjugular intrahepatic portosystemic shunt, and according to the latest evidence, Child-Pugh C has better prognostic relevance $[28,29]$ than Child-Pugh B and active bleeding at endoscopy. Our real life cohort confirmed these findings although the patients were not specifically evaluated for early TIPS insertion. Active bleeding was not associated with either FTB or 42-day survival, unlike Child-Pugh score, which was independently associated with both end-points.

However, contrary to the previous reports, we did not find an influence of comorbidities (CirCom and Charlson indices) on the failure to control bleeding. Our results may be biased due to the small number of patients in the comorbidity group and to the low comorbidity scores. Nevertheless, it is important to mention that AKI has a significant influence on the failure to control bleeding. Both the creatinine level per se and the association of kidney failure (defined as a creatinine level above $1.5 \mathrm{mg} / \mathrm{dl}$ ) were associated significantly with rebleeding at 5 days, possibly due to the severity of bleeding as well as that of the main condition. This particular fact has had little coverage in the literature so far. On the other hand, the correlation between kidney injury and ascites during liver cirrhosis is well known.

Among the factors associated with both endpoints, we found that creatinine is strongly and independently associated with 42-day mortality in the model that did not include the MELD score. This finding is in concordance with other data, where renal failure is associated with a 7-fold increase in mortality, with half of patients dying in the first month [30]. After the recent publication of the new criteria of AKI [31], which discourages the use of the $1.5 \mathrm{mg} / \mathrm{dl}$ threshold for serum creatinine, the biggest challenge is to diagnose AKI in the absence of baseline serum creatinine. In our cohort, in the absence of baseline serum creatinine levels, we successfully identified patients with higher mortality using the $1.5 \mathrm{mg} / \mathrm{dl}$ threshold. One of the limitations of our study is that, in the absence of infectious symptoms, the included patients had no extensive infectious work-up at the inclusion, and thus we cannot analyze the relation between $\mathrm{AKI}$ and bacterial infections, both associated with bad prognosis in patients with variceal bleeding [32]. However, as the guidelines recommend [33] all patients received prophylactic antibiotherapy and none presented persistent renal failure at discharge. We previously demonstrated that presence of AKI and bacterial infections were independently associated with in-hospital mortality in patients with decompensated cirrhosis (mainly ascites) [34]. Although there is strong evidence that bacterial infections frequently determine AKI, we believe that we cannot speak only about a cause-effect relation between AKI, bacterial infections and survival.

The significant difference in the time interval between the apparent bleeding and the moment of the endoscopy deserves to be mentioned. From our knowledge there are limited data regarding the relation between time intervals (from symptoms onset to endoscopy and from admission to hospital to endoscopy) and the prognosis of the patients with variceal bleeding. Time from symptoms onset to endoscopy was significantly shorter in patients with FTB, due to the more rapid transfer of severe patients to the endoscopy department. When time from admission to endoscopy was analyzed we found no difference between patients with and without FTB, demonstrating that in a tertiary health care center, the recommendation of rapid endoscopy (in the first $12 \mathrm{~h}$ ) is followed. The difference is created by the interval between symptoms onset and admission to the hospital, which is significantly shorter in severe patients. In multivariate analysis, only the Child class was significantly associated with failure to control bleeding, which is a marker of the real influence of main disease severity. Therefore, ChildPugh class $C$ may be used as an indicator for rapid transfer to a 24-hour endoscopy facility.

At the 6-week check-up, the mortality in our group was $21.47 \%$. Our results are similar to those reported by d'Amico et al., but higher than the values of $14.5-18.4 \%$ reported in other studies [10-12, 35].

In concordance with the previous reports, in our study the factors associated with 42-day mortality were mainly those depending on the liver function, such as the Child-Pugh [12, 25, 36, 37] and MELD scores [38, 39], total bilirubin [40, 41], INR [40, 42], ascites [41], hepatic encephalopathy [25, 43] or albumin [44]. Regarding the endoscopic risk factors, we failed to demonstrate any association between active bleeding at endoscopy and FTB or 
42-day death. However, as expected, the patients with FTB had higher 42-day mortality and the hemodynamic instability as a sign of severe bleeding was correlated with FTB, similar to previous reports $[11,12]$.

The factors most strongly associated with the end-points were the Child-Pugh and MELD score, and among the variables used in their calculation, the largest impact was exerted by creatinine for MELD and encephalopathy for the Child-Pugh score. Only encephalopathy among the ChildPugh variables $(\mathrm{OR}=3.84,95 \% \mathrm{Cl}: 1.44-10.25$, $p=0.007)$ and only creatinine among the MELD score variables $(\mathrm{OR}=3.65,95 \% \mathrm{Cl}: 1.40-9.51$, $p=0.008)$ were independently associated with 42-day mortality. The MELD score was proven to have the highest discriminative value for 42-day mortality prediction, with the best cut-off of 19 [5], which is very similar to our cut-off value of 18 . On the other hand, the Child score remains widely used in clinical practice and research, for being superior to other scores studied for the prediction of mortality 6 weeks after variceal bleeding [25, 45, 46]. It is worth noting that both the score per se as well as its variables were identified as predictive factors for bleeding [47]. The score is easy to use at the bedside, requiring just a simple mathematical calculation, but has some disadvantages related to the subjective assessment of encephalopathy and ascites severity. However, it is generally accepted that liver function is the most important factor associated with short-term prognosis after variceal bleeding.

In our population, we did not observe any association between comorbidities quantified by the Charlson and CirCom scores and the 42-day prognosis. However, these score were not created to predict short-term prognosis and, moreover, the Charlson score is not intended for patients with cirrhosis. Acute kidney injury already present at admission appears to be an important prognostic factor and the nutritional status seems to be also important [48], but more studies are needed to confirm these findings. In addition, new diagnostic criteria need further validation in the setting of variceal bleeding.

This study has certain strengths and limitations. It reports the experience of a single referral center, which may be considered a limitation, but our institute is the referral center for treating variceal bleeding in a large region. Furthermore, the data were included prospectively and the patients were carefully followed for at least 6 weeks and therefore we consider the data to be representative for the Eastern-European region. On the other hand, we are aware of the absence of minimally invasive therapy of urgent decrease of portal hypertension (early TIPS), and consequently, this study has analyzed only the factors associated with mortality and rebleeding in patients treated conservatively. In this context, the hepatic venous pressure gradient (HVPG) was not assessed in our patients, so as to evaluate its influence on the failure to control bleeding and on mortality. Another limitation of the study is the lack of baseline serum creatinine values (before the bleeding) in order to apply the new diagnostic criteria of renal dysfunction [31] and to better quantify the influence of renal dysfunction on prognosis.

In conclusion, the severity of cirrhosis is an important prognostic factor for FTB and 42-day mortality. Despite the substantial improvements made in the therapy of variceal bleeding, mortality remains high, especially in severe patients [49]. Identifying the factors associated with rebleeding and early mortality may help in selecting from the beginning the patients in need of more than just conventional therapy. New studies assessing the importance of portal venous pressure and even emergency vascular interventions are needed in order to improve the management of these patients.

\section{Conflict of interest}

The authors declare no conflict of interest.

\section{References}

1. Thuluvath PJ. Management of upper gastrointestinal hemorrhage related to portal hipertension. In: Yamada T, Alpers DH, Kalloo AN, Kaplowitz N, Owyang C, Powell W (eds.). Textbook of gastroenterology. $5^{\text {th }}$ ed. Lippincott Williams \& Wilkins, Philadelphia 2009; 2987-3017.

2. Sanyal AJ. General principles of the management of variceal hemorrhage. http://www.uptodate.com, 2013, This topic last updated: Aug 20, 2012, accessed 15 Nov 2013.

3. Pugh RN, Murray-Lyon IM, Dawson JL, Pietroni MC, Williams R. Transection of the oesophagus for bleeding oesophageal varices. Br J Surg 1973; 60: 646-9.

4. Kamath PS, Wiesner RH, Malinchoc M, et al. A model to predict survival in patients with endstage liver disease. Hepatology 2001; 33: 464-47.

5. Reverter E, Tandon P, Augustin S, et al. A MELD-based model to determine risk of mortality among patients with acute variceal bleeding. Gastroenterology 2014; 146: 412-19.

6. Chalasani N, Kahi C, Francois F, et al. Model for endstage liver disease (MELD) for predicting mortality in patients with acute variceal. Hepatology 2002; 35: 1282-4.

7. Lee JY, Lee JH, Kim SJ, et al. Comparison of predictive factors related to the mortality and rebleeding caused by variceal bleeding: Child-Pugh score, MELD score, and Rockall score. Taehan Kan Hakhoe Chi 2002; 8: 458-64.

8. Jepsen P, Vilstrup H, Lash TL. Development and validation of a comorbidity scoring system for patients with cirrhosis. Gastroenterology 2014; 146: 147-56.

9. Graham DY, Smith JL. The course of patients after variceal hemorrhage. Gastroenterology 1981; 80: 800-9.

10. Carbonell N, Pauwels A, Serfaty L, Fourdan O, Lévy VG, Poupon R. Improved survival after variceal bleeding 
in patients with cirrhosis over the past two decades. Hepatology 2004; 40: 652-9.

11. Chalasani N, Kahi C, Francois F, et al. Improved patient survival after acute variceal bleeding: a multicenter, cohort study. Am J Gastroenterol 2003; 98: 653-9.

12. Thomopoulos K, Theocharis G, Mimidis K, Lampropoulou-Karatza Ch, Alexandridis E, Nikolopoulou V. Improved survival of patients presenting with acute variceal bleeding. Prognostic indicators of short- and long-term mortality. Dig Liver Dis 2006; 38: 899-904.

13. Stokkeland K, Brandt L, Ekbom A, Hultcrantz R. Improved prognosis for patients hospitalized with esophageal varices in Sweden 1969-2002. Hepatology 2006; 43: 500-5.

14. D’Amico G, De Franchis R; Cooperative Study Group. Upper digestive bleeding in cirrhosis. Post-therapeutic outcome and prognostic indicators. Hepatology 2003; 38: 599-612.

15. de Franchis R, Primignani M. Why do varices bleed? Gastroenterol Clin North Am 1992; 21: 85-101.

16. Albillos Martínez A. Survival of patients with cirrhosis after acute variceal bleeding. Rev Esp Enferm Dig 2009; 101: 231-5.

17. Salerno F, Gerbes A, Gines P, et al. Diagnosis, prevention and treatment of the hepatorenal syndrome in cirrhosis a consensus workshop of the International Ascites Club. Gut 2007; 56: 1310-8.

18. Charlson ME, Pompei P, Ales KL, MacKenzie CR. A new method of classifying prognostic comorbidity in longitudinal studies: development and validation. J Chronic Dis 1987; 40: 373-83.

19. de Franchis R; Baveno V Faculty. Revising consensus in portal hypertension: report of the Baveno $V$ consensus workshop on methodology of diagnosis and therapy in portal hypertension. J Hepatol 2010; 53: 762-8.

20. Krige JEJ, Shaw JM, Bornman PC. The evolving role of endoscopic treatment for bleeding esophageal varices. World J Surg 2005; 29: 966-73.

21. Krige JEJ, Beningfield SJ, Shaw J. Management of bleeding oesophageal varices. In: Recent Advances in Surgery. Johnson C, Taylor I (eds.). $30^{\text {th }}$ ed. Royal Society of Medicine, London 2007; 105-25.

22. Zhao C, Chen SB, Zhou JP, et al. Prognosis of hepatic cirrhosis patients with esophageal or gastric variceal hemorrhage: multivariate analysis. Hepatobiliary Pancreat Dis Int 2002; 1: 416-9.

23. Jalan R, Hayes PC. UK guidelines on the management of variceal haemorrhage in cirrhotic patients. British Society of Gastroenterology. Gut 2000; 46 (Suppl 3-4): III1-III15

24. Poynard T, Lebrec D, Hillon P, et al. Propranolol for prevention of recurrent gastrointestinal bleeding in patients with cirrhosis: a prospective study of factors associated with rebleeding. Hepatology 1987; 7: 447-51.

25. Sanders DS, Carter MJ, Goodchap RJ, Cross SS, Gleeson DC, Lobo AJ. Prospective validation of the Rockall risk scoring system for upper GI hemorrhage in subgroups of patients with varices and peptic ulcers. Am J Gastroenterol 2002; 97: 630-5.

26. Bosch J, Berzigotti A, Garcia-Pagan JC, et al. The management of portal hypertension: rational basis, available treatments and future options. J Hepatol 2008; 48 (Suppl 1): S68-S92.

27. Ben-Ari Z, Cardin F, McCormick AP, et al. A predictive model for failure to control bleeding during acute variceal haemorrhage. J Hepatol 1999; 31: 443-50.
28. Deltenre P, Trépo E, Rudler M, et al. Early transjugular intrahepatic portosystemic shunt in cirrhotic patients with acute variceal bleeding: a systematic review and meta-analysis of controlled trials. Eur J Gastroenterol Hepatol 2015; 27: e1-9.

29. Hernández-Gea V, Procopet B, Giráldez Á, et al. Preemptive-TIPS improves outcome in high-risk variceal bleeding an observational study. Hepatology 2019; 69: 282-93.

30. Fede G, D’Amico G, Arvaniti V, et al. Renal failure and cirrhosis: a systematic review of mortality and prognosis. J Hepatol 2012; 56: 810-8.

31. Angeli $P$, Ginès $P$, Wong $F$, et al. Diagnosis and management of acute kidney injury in patients with cirrhosis: revised consensus recommendations of the International Club of Ascites. J Hepatol 2015; 62: 968-74.

32. Hsieh YC, Lee KC, Chen PH, Su CW, Hou MC, Lin HC. Acute kidney injury predicts mortality in cirrhotic patients with gastric variceal bleeding. J Gastroenterol Hepatol 2017; 32: 1859-66.

33. de Franchis R.; Baveno VI Faculty. Expanding consensus in portal hypertension: Report of the Baveno VI Consensus Workshop: stratifying risk and individualizing care for portal hypertension. J Hepatol 2015; 63: 743-52

34. Pop A, Fischer P, Stefanescu H, et al. Dangerous liaison: infection - acute kidney injury - mortality. THU-023A J Hepatol 2016 Suppl 2; 64.

35. Boix J, Lorenzo-Zuniga V, Moreno de Vega V, et al. Sclerotherapy and esophageal variceal bleeding: time to forget it, or not? Endoscopy 2007; 39: 478.

36. Bosch J, Abraldes JG, Groszmann R. Current management of portal hypertension. Hepatology 2003; 38 : S54-68.

37. Yang MT, Chen HS, Lee HC, et al. Risk factors and survival of early bleeding after esophageal variceal ligation. Hepatogastroenterology 2007; 54: 1705-9.

38. Krige JEJ, Kotze UK, Bornman PC, et al. Recurrence, rebleeding and survival after endoscopic injection sclerotherapy in alcoholic patients with bleeding esophageal varices. Ann Surg 2006; 244: 764-70.

39. Amitrano L, Guardascione MA, Bennato R, et al. MELD score and hepatocellular carcinoma identify patients at different risk of short-term mortality among cirrhotics bleeding from esophageal varices. J Hepatol 2005; 42 820-5.

40. Lata J, Husova L, Jurankova J, et al. Factors participating in the development and mortality of variceal bleeding in portal hypertension - possible effects of the kidney damage and malnutrition. Hepatogastroenterology 2006; 53: 420-5.

41. Hori S, Takaki A, Okada H, et al. Endoscopic therapy for bleeding esophageal varices improves the outcome of Child C cirrhotic patients. J Gastroenterol Hepatol 2006; 21: 1704-9.

42. Le Moine O, Adler M, Bourgeois N, et al. Factors related to early mortality in cirrhotic patients bleeding from varices and treated by urgent sclerotherapy. Gut 1992; 33: $1381-5$

43. Srikureja W, Kyulo NL, Runyon BA, et al. MELD score is a better prognostic model than Child-Turcotte-Pugh score or discriminant function score in patients with alcoholic hepatitis. J Hepatol 2005; 42: 700-6.

44. Lo GH, Chen WC, Chen MH, et al. The characteristics and the prognosis for patients presenting with actively bleeding esophageal varices at endoscopy. Gastrointest Endosc 2004; 60: 714-20.

45. Garcia-Tsao G, Bosch J, Groszmann RJ. Portal hypertension and variceal bleeding-unresolved issues. Summary 
of an American Association for the Study of Liver Diseases and European Association for the Study of the Liver single-topic conference. Hepatology 2008; 47 . 1764-72.

46. Atkinson RJ, Hurlstone DP. Usefulness of prognostic indices in upper gastrointestinal bleeding. Best Pract Res Clin Gastroenterol 2008; 22: 233-42.

47. D’Amico G, Garcia-Tsao G, Pagliaro L. Natural history and prognostic indicators of survival in cirrhosis: a systematic review of 118 studies. J Hepatol 2006; 44: 217-31.

48. Gao L, Meng F, Cheng J, Li H, Han J, Zhang W. Prediction of oesophageal varices in patients with primary biliary cirrhosis by non-invasive markers. Arch Med Sci 2017; 13: 370-376.

49. Thabut D, Bernard-Chaber TB. Management of acute bleeding from portal hypertension. Best Pract Res Clin Gastroenterol 2007; 21: 19-29. 